\title{
Transcriptional Cascade in the Regulation of Flowering in the Bamboo Orchid Arundina graminifolia
}

\author{
Sagheer Ahmad (D, Chuqiao Lu, Jieqiu Wu, Yonglu Wei, Jie Gao, Jianpeng Jin, Chuanyuan Zheng, Genfa Zhu * \\ and Fengxi Yang *
}

Citation: Ahmad, S.; Lu, C.; Wu, J.; Wei, Y.; Gao, J.; Jin, J.; Zheng, C.; Zhu, G.; Yang, F. Transcriptional Cascade in the Regulation of Flowering in the Bamboo Orchid Arundina graminifolia. Biomolecules 2021, 11, 771. https:// doi.org/10.3390/biom11060771

Academic Editor: Mohamed

A. El-Esawi

Received: 1 April 2021

Accepted: 17 May 2021

Published: 21 May 2021

Publisher's Note: MDPI stays neutral with regard to jurisdictional claims in published maps and institutional affiliations.

Copyright: (c) 2021 by the authors. Licensee MDPI, Basel, Switzerland. This article is an open access article distributed under the terms and conditions of the Creative Commons Attribution (CC BY) license (https:// creativecommons.org/licenses/by/ $4.0 /)$.
Guangdong Key Laboratory of Ornamental Plant Germplasm Innovation and Utilization, Environmental Horticulture Research Institute, Guangdong Academy of Agricultural Sciences, Guangzhou 510640, China; sagheerhortii@gmail.com (S.A.); luchuqiao@gdaas.cn (C.L.); Jieqiu2021520@163.com (J.W.); weiyonglu@gdaas.cn (Y.W.); gaojie@gdaas.cn (J.G.); jinjianpeng@gdaas.cn (J.J.); zcytrain@zhku.edu.cn (C.Z.)

* Correspondence: zhugenfa@gdaas.cn (G.Z.); yangfengxi@gdaas.cn (F.Y.); Tel.: +86-020-8759-6566 (G.Z.); +86-020-8516-1014 (F.Y.)

\begin{abstract}
Flowering in orchids is the most important horticultural trait regulated by multiple mechanisms. Arundina graminifolia flowers throughout the year unlike other orchids with a narrow flowering span. However, little is known of the genetic regulation of this peculiar flowering pattern. This study identifies a number of transcription factor (TF) families in five stages of flower development and four tissue types through RNA-seq transcriptome. About 700 DEGs were annotated to the transcription factor category and classified into $35 \mathrm{TF}$ families, which were involved in multiple signaling pathways. The most abundant TF family was bHLH, followed by MYB and WRKY. Some important members of the bHLH, WRKY, MYB, TCP, and MADS-box families were found to regulate the flowering genes at transcriptional levels. Particularly, the TFs WRKY34 and ERF12 possibly respond to vernalization and photoperiod signaling, MYB108, RR9, VP1, and bHLH49 regulate hormonal balance, and CCA1 may control the circadian pathway. MADS-box TFs including MADS6, 14, 16, AGL5, and SEP may be important regulators of flowering in A. graminifolia. Therefore, this study provides a theoretical basis for understanding the molecular mechanism of flowering in A. graminifolia.
\end{abstract}

Keywords: Arundina graminifolia; flowering; transcriptome; transcription factor

\section{Introduction}

Flowering is the key developmental stage resulting from vegetative to reproductive transition [1]. Plants have developed several genetic mechanisms to assure flowering in various environmental conditions. These mechanisms are regulated by intrinsic and extrinsic signals [2]. To date, six flowering control pathways have been presented, including the ambient temperature pathway, vernalization pathway, circadian clock pathway, photoperiod pathway, gibberellin pathway, and autonomous pathway [3]. In the vernalization, photoperiod, and ambient temperature pathways, light and temperature act as extrinsic signals and are important environmental factors in the control of flowering [3,4]. Intrinsic signals are received by the circadian pathway, gibberellin pathway, and autonomous pathway to regulate flowering [5-7].

In the model angiosperm Arabidopsis thaliana, flowering time depends on five genetic pathways: the vernalization, gibberellin, photoperiod, aging, and autonomous pathways [8]. These pathways are integrated by the function of the genes, including FLOWERING LOCUS T (FT), SUPPRESSOR OF OVEREXPRESSION OF CO 1 (SOC1) and FLOWERING LOCUS D (FD) [8-10]. These integrators transmit the floral induction signals to the floral meristem identity genes APETALA1 (AP1) and LEAFY (LFY), which initiate the floral morphogenesis program. Then, floral organs develop under the control of MADS-box genes and their co-regulators [10]. In the photoperiod pathway, cryptochrome 
and phytochrome photoreceptors detect light signals and retune the feedback loop of the circadian clock, including the timing of cab expression 1 (TOC1), CIRCADIAN CLOCK ASSOCIATED 1 (CCA1) and late elongated hypocotyl (LHY) [11,12]. Constans (CO) plays an important role in the biological clock and photoperiod pathways and promotes flowering through the transcription of the flowering locus T (FT) [12-14]. MADS-box TF and FLC (flowering locus C) repress flowering by preventing FT and SOC1 (suppressor of overexpression of CO1) [15]. However, the FLC transcription is repressed by VRN2 (vernalization 2) and VRN3 (vernalization 3) in the vernalization pathway to promote flowering $[13,14,16,17]$. The short vegetative phase (SVP) is another MADS-box TF that plays a role in the ambient temperature pathway. It negatively regulates FT to negate flowering [18]. The autonomous pathway downregulates FLC transcription and promotes flowering [6]. Gibberellin 20 oxidase (GA20ox) is involved in the GA biosynthesis [2]. It accumulates abundantly in the meristem just before floral induction and promotes flowering by upregulating SOC1 [5]. SPL (squamosa promoter binding protein-like) TFs, which are targeted and depressed by miR156 [19], increase in the circadian clock pathway and promote flowering by upregulating flowering genes, such as FRUITFUL (FUL) and SOC1 [2].

In the plant kingdom, flower development is arguably the most intricate developmental process. Most of the major hormones have been proposed to play roles in flower development, including ABA [20], GA [21], auxin [22], cytokinin [23], jasmonate [24], and ethylene [25]. Although the model plants provide a useful source for the identification and functional characterization of flowering genes, studying these genes in other plants growing in peculiar environments or with unique characteristics is vital to further deepen the molecular basis of flowering regulation. Arundina graminifolia, commonly called 'bamboo orchid', is an important flower in the family Orchidaceae. It mainly grows in tropical and sub-tropical areas in Asia and has been used as a traditional medicinal plant in China and an ornamental flower in Singapore and Malaysia [26-28]. Unlike other orchids, it blooms throughout the year with flowering peaks from September to January. However, the molecular mechanism of flowering in A. graminifolia remains unclear. Therefore, the present study uses transcriptome data to mine transcription factor families and important TFs involved in flowering in A. graminifolia. Specific results from this study will aid the further understanding of genetic regulation of flowering in orchids.

\section{Materials and Methods}

\subsection{Plant Materials and Growth Conditions}

Arundina graminifolia plants were grown at the greenhouse of Environmental Horticultural Research Institute of Guangdong Academy of Agricultural Sciences, China $\left(23^{\circ} 9^{\prime} \mathrm{N}, 113^{\circ} 21^{\prime} 10^{\prime \prime} \mathrm{E}\right)$. Each cluster contained 3 to 4 plants with a cluster distance of $10 \mathrm{~cm}$ $\times 10 \mathrm{~cm}$. Plants were grown at a photoperiod of $16 / 8 \mathrm{~h}$ with a day/night temperature of $25 / 20{ }^{\circ} \mathrm{C}$. Samples were collected from five stages (stage 1-5) of floral development (FD), flowers, silique, leaves, and root. Sampling was done in three biological and technical repetitions for each floral development stage and tissue type. All the samples were collected in liquid nitrogen and immediately stored at $-80^{\circ} \mathrm{C}$ for further processing.

\subsection{Horticultural and Flowering Characteristics Assessmenet from Different Sources}

Horticultural traits and flowering characteristics of A. graminifolia were observed from four different sources, including Guangdong (China), Hainan (China), Singapore, and Malaysia. The data were recorded for plant height, number of blades, leaf length, leaf width, stem diameter, flowering period, and capsule color (Table 1). A total of 20 plants were observed from each source. Leaf characteristics were measured from the strongest and most adult leaves, i.e., the 4 th and 5 th leaf. Stem diameter was measured from the widest part of stem, i.e., the middle of the stem. 
Table 1. Horticultural characters and flowering characteristics of A. graminifolia from different sources.

\begin{tabular}{|c|c|c|c|c|c|c|c|}
\hline Origin & $\begin{array}{c}\text { Plant Height } \\
(\mathrm{cm})\end{array}$ & $\begin{array}{l}\text { Number of } \\
\text { Blades (cm) }\end{array}$ & $\begin{array}{l}\text { Leaf Length } \\
\text { (cm) }\end{array}$ & $\begin{array}{l}\text { Leaf Width } \\
\text { (cm) }\end{array}$ & $\begin{array}{c}\text { Stem Diameter } \\
\text { (cm) }\end{array}$ & Flowering Period & Silique \\
\hline Guangdong, China & $36.43 \pm 1.53$ & $18.74 \pm 0.75$ & $10.56 \pm 0.48$ & $0.81 \pm 0.03$ & $0.32 \pm 0.02$ & Throughout the year & Purple \\
\hline Hainan, China & $31.09 \pm 1.42$ & $18.33 \pm 0.84$ & $11.59 \pm 0.53$ & $0.82 \pm 0.03$ & $0.31 \pm 0.01$ & Throughout the year & Green \\
\hline Singapore & $80.34 \pm 1.89$ & $31.03 \pm 0.97$ & $12.30 \pm 0.64$ & $0.85 \pm 0.04$ & $0.42 \pm 0.02$ & Throughout the year & Green \\
\hline Malaysia & $142.16 \pm 3.32$ & $34.17 \pm 0.94$ & $13.41 \pm 0.49$ & $0.79 \pm 0.03$ & $0.49 \pm 0.01$ & Throughout the year & Green \\
\hline
\end{tabular}

\subsection{RNA-Seq Library Preparation and Sequencing}

RNA was extracted from 9 tissues (5 FD stages, flower, silique, root, and leaf) using a TaKaRa RNA extraction kit, followed by the construction of cDNA libraries. Oligotex mRNA Midi Kit (QIAGEN, Hilden, Germany) was used to filter mRNAs from total RNA. RNA quantity and quality was checked on a Nano-Dropt 2000 spectrophotometer (Thermo Scientific, Waltham, MA, USA), followed by cDNA library preparation using Illumina manufacturing protocol. The mRNAs were fragmented to an approximate length of $200 \mathrm{bp}$. The first and second strand cDNA was synthesized from the isolated mRNAs, followed by adapter ligation and low-cycle enrichment according to TruSeq ${ }^{\circledR}$ RNA HT Sample Prep Kit (Illumina, San Diego, CA, USA). The purified library products were evaluated using Agilent 2200 TapeStation and Qubit ${ }^{\circledR} 2.0$ (Life Technologies, Waltham, MA, USA) and diluted to $10 \mathrm{pM}$ to generate clusters in situ on the HiSeq2500 pair-end flow cell. Sequencing $(2 \times 100 \mathrm{bp})$ was performed. Each sample produced about 60 million reads. Transcriptome de novo was done using the Trinity program with default parameters [29].

\subsection{Analysis of DEGs}

Gene expression was calculated by RPKM values using the following formula:

$$
\mathrm{RPKM}=[\text { total exon reads } / \text { mapped reads (millions) }] \times \text { exon length }(\mathrm{kb})
$$

The edgeR package was used to determine the significant difference among tissues. The threshold $p$-value was determined using the false discovery rate (FDR) at FDR $<0.05$ and $\mid \log 2$ ratio $\mid>1$ (two-fold change). We screened the DEGs with an FDR threshold of 0.05 or less and the log2 ratio of one or more. The DEGs were annotated to the gene ontology (GO) and Kyoto Encyclopedia of Genes and Genomes (KEGG) databases (http:/ / www.geneontology.org/or http:/ / www.genome.ad.jp/; accessed on 5 November 2018) to calculate gene enrichment for biological processes or KEGG pathways. Genetically enriched DEGs were found using a hypergeometric test. Significantly enriched GO terms or KEGG pathways were filtered at a $p$ or $q$ value of $\leq 0.05$.

\subsection{GO Biological Process Enrichment for Flowering}

Of the 25,353 DEGs, about 1000 DEGs were filtered according to flower development, flowering time regulation, circadian clock, and hormonal regulation. The annotated gene IDs were run on ShinyGO (Gene Ontology Enrichment Analysis; v0.61) to perform network analysis and connection tree analysis.

\subsection{Filtering of TF Families}

The term transcription factor was searched across DEG annotations and sorted 687 terms labeled as transcription factors. The filtered terms were sorted to find the subsets of major TF families.

\subsection{Identification of Significantly Differential and Stage Specific Tfs}

Top 20 highly differential TFs were identified across all the samples using the edgeR package of $R$.

Preferentially expressed/stage specific genes were mined using a stage specificity (SS) scoring algorithm. This algorithm compares the gene expression in a specific stage with 
its maximum expression in other stages [30]. The higher SS score of a gene in a particular stage signifies its expression at that stage. SS scores were used to draw a heatmap using ggplot2 utility in R.

\subsection{Quantitative Real-Time PCR Analysis}

Highly expressed stage specific genes were selected for validation through qRT-PCR. RNA was extracted from 9 tissues and cDNA was obtained using the protocol by Fermentas. The qRT-PCR was performed in a reaction mixture of $20 \mu \mathrm{L}$ containing $10 \mu \mathrm{L}$ of SYBR premix Ex-taq ${ }^{\mathrm{TM}}$ (Takara, Kusatsu, Japan) using Bio-Rad CFX-96 RealTime PCR System (Bio-Rad, Hercules, California, USA). Actin was used for the internal standardization. Three biological and technical repeats were performed for each sample.

\subsection{Statistical Analysis}

ANOVA (one-way) was used in SPSS software (SPSS Inc., Chicago, IL, USA; ver. 16.0) to judge the statistical significance of data. Significant differences are shown at $p<0.05$ or $p<0.01$ level.

\section{Results}

\subsection{Flowering Habit of A. graminifolia}

A. graminifolia starts the reproductive cycle after six months of vegetative growth. This time span is very short compared to other orchids, such as Cymbidium and Phalaenopsis, taking 2-3 years to complete the juvenile phase. Moreover, it flowers throughout the year, with flowering peaks between September and January (Table 1). The average life of a single flower is about one month. The flower development is completed in five stages, starting from stage 1 to the fully formed flower (stage 5). The mature flower bears a column in the center with four pollinia arranged in a semi-circle around it (Supplementary Figure S1). To obtain a comprehensive understanding of the genetic regulation of flower development, we performed transcriptome analysis from five stages of floral development, mature flowers, silique, root, and leaves.

\subsection{RNA-Seq and Functional Annotation}

The transcriptome analysis produced about 71.2 billion reads from five development stages and four tissue types. Each sample generated about 10.8-12.8 Gb data with an average of 7.8 billion reads. We filtered 25,353 differentially expressed unigenes (DEGs), which were annotated using GO, KEGG, Pfam, eggNOG, and NR databases, covering annotation data of $67.73 \%, 36.42 \%, 64.18 \%, 56.54 \%, 74.37 \%$, and $72.29 \%$, respectively (Supplementary Table S1).

\subsection{Biological Process Enrichment of Hormonal and Flowering Related DEGs}

About 1000 DEGs were filtered according to flower development, flowering time regulation, circadian clock, and hormonal regulation. The biological process enrichments of these DEGs show some clusters related to hormonal regulation and flowering (Figure 1a,b). In gibberellic acid regulation, GA-mediated signaling pathway (GO: 0009740) and response to gibberellin (GO: 0009739) were the most abundant biological process terms enriched by 43 and 52 DEGs, respectively. In the abscisic acid regulation, the ABAactivated signaling pathway (GO: 0009738) and response to ABA (GO: 0009737) were the most abundant biological processes enriched by 138 and 237 DEGs, respectively. Auxin transport (GO: 0060918), Auxin biosynthetic process (GO: 0009851), auxin homeostasis (GO: 0010252), auxin polar transport (GO: 0009926, auxin activated signaling pathway (GO: 0009734), and response to auxin (GO: 0009733) were shown by 9, 10, 18, 34, and 141 DEGs, respectively. The cytokinin biosynthetic process (GO: 0009691), cytokininactivated signaling pathway (GO: 0009736), and response to cytokinin (0009735) were regulated by 8, 33, and 91 DEGs, respectively. Response to sucrose (GO: 0009744), sucrose 
biosynthetic process (GO: 0005986), and sucrose transport (GO: 0015770) were the abundant processes in the sucrose regulation regulated by 42,12 , and 12 DEGs, respectively (Figure 1c).

a

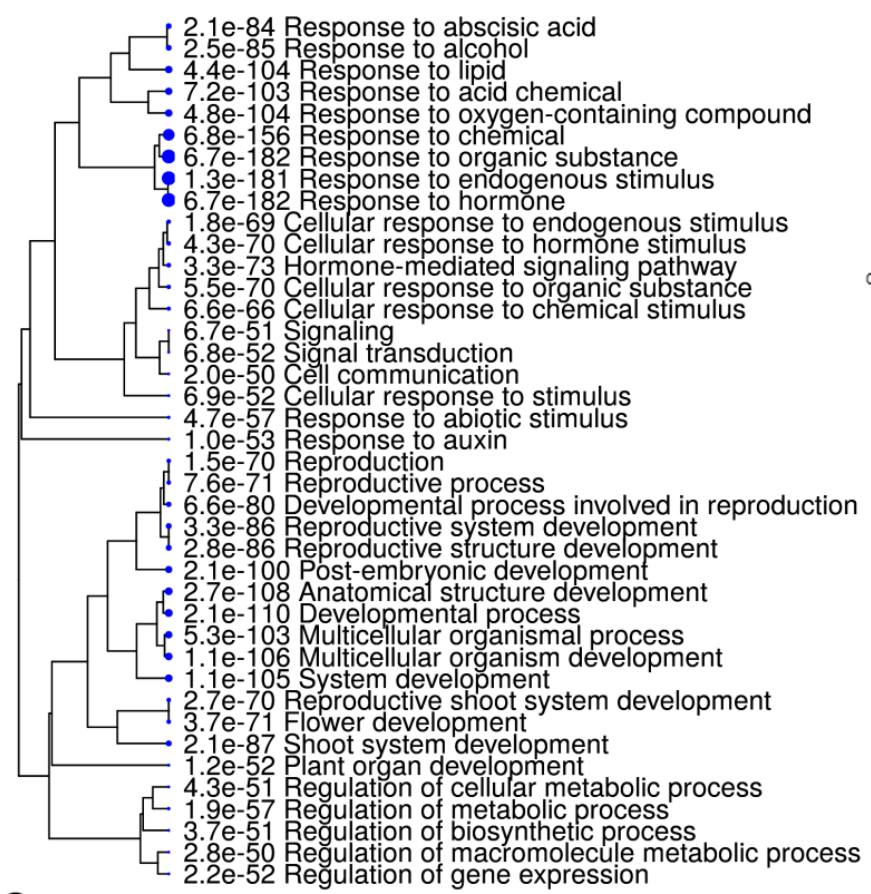

C

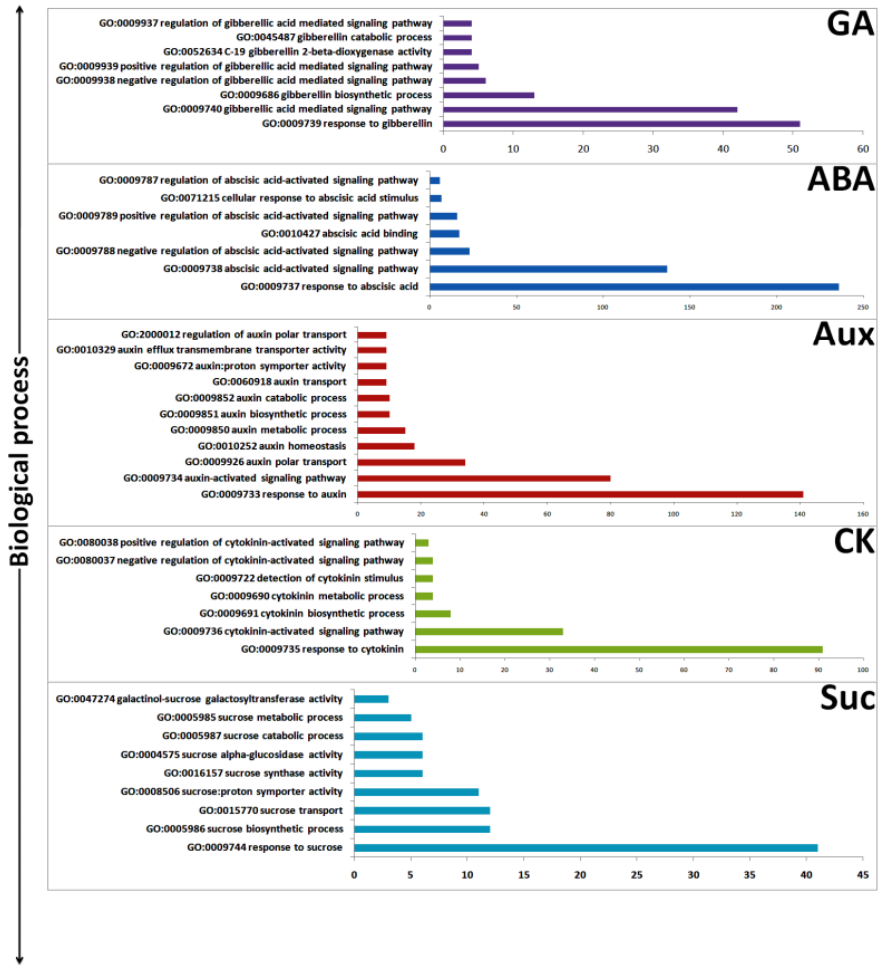

b
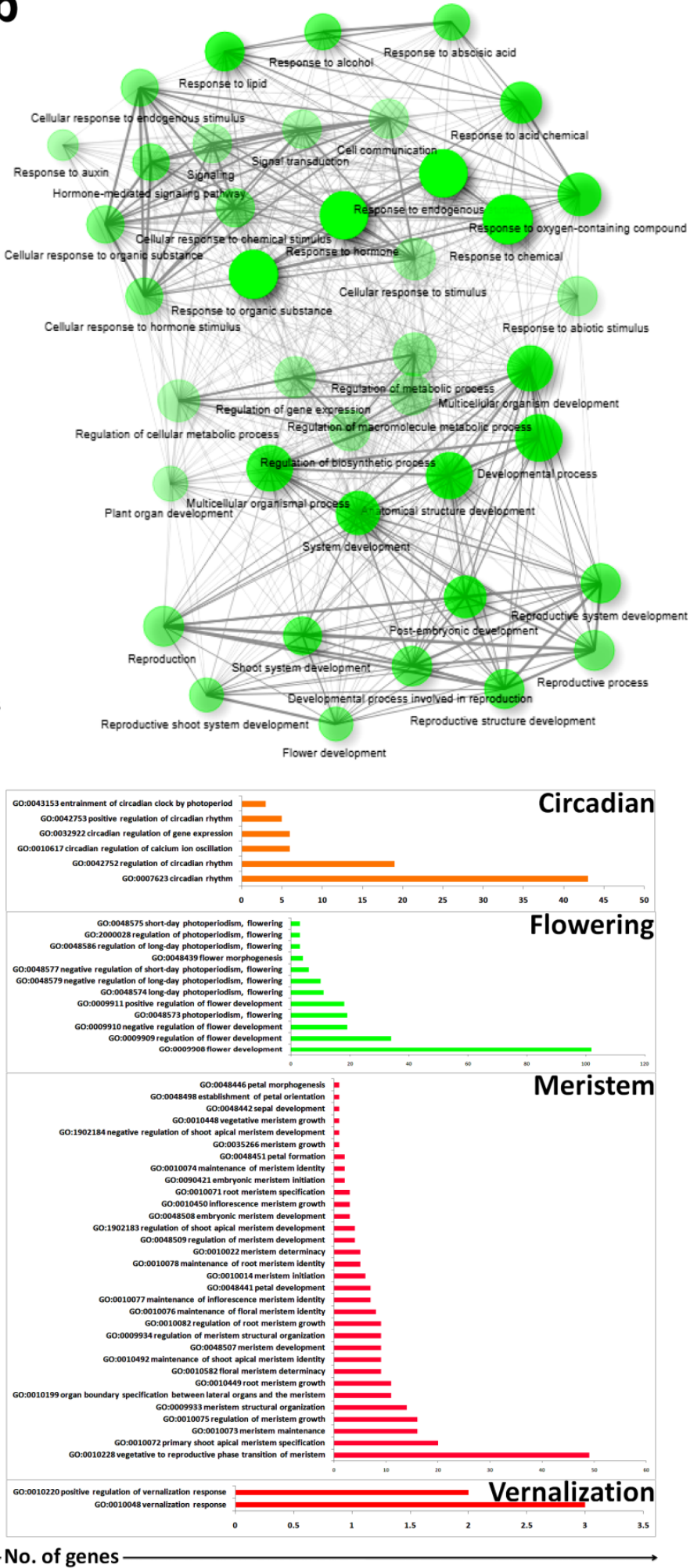

Figure 1. GO (Gene Ontology) biological process annotation; (a) interconnections of important abundant biological processes, (b) clustering of biological processes of flowering and hormonal related DEGs, (c) GO ids of biological processes specific to hormones and flowering regulatory pathways and meristem. 
The circadian rhythm (GO: 0007623) and the regulation of the circadian rhythm (GO: 0042752) were the most abundant biological processes in the circadian regulation regulated by 44 and 19 DEGs, respectively. A few DEGs were involved in the vernalization response (GO: 0010048). The DEGs enriched in the long day photoperiodism and flowering (GO: 0048574), negative regulation of flower development (GO: 0009910), photoperiodism and flowering (GO: 0048573), positive regulation of flower development (GO: 0009911), regulation of flower development (GO: 000909), and flower development (GO: 0009908) were $11,19,19,35$, and 102 , respectively. In the organ specification, vegetative to reproductive phase transition of meristem (GO: 0010228), petal development (GO: 0048441), regulation of meristem growth (0010075), primary shoot apical meristem specification (0010072), floral meristem determinacy (GO: 0010852), maintenance of flora meristem identity (GO: 0010076), and maintenance of inflorescence meristem identity (GO: 0010077) were the important biological processes regulated by 50, 7, 16, 21, 9, 8, and 7 DEGs, respectively (Figure 1c).

\subsection{Filtering of Transcription Factor (TF) Families}

The term 'Transcription Factor' was searched across annotations to find DEGs related to transcriptional activity. We found about 700 DEGs involving transcriptional activity, which were divided into 35 different families. A number of famous families were found in our transcriptome data, including bHLH, MYB, WRKY, EFF, bZIP, CYC, MADS, TCP, and NAC (Figure 2a). The bHLH was the most abundant TF family, containing more than 70 members (Figure 2b), followed by MYB, containing about 50 members (Figure 2c), and WRKY, containing more than 45 members (Figure 2d). The bHLHs were mainly expressed in the root, leaf, and early stages of flower development, especially in FD1. The MYBs were also expressed in the root, leaf, and early stages of flower development. However, the WRKYs were expressed abundantly in the flower and root compared to other floral development stages or tissue types.

\subsection{Tissue-Specific Up and Down Regulation of TFs}

Interesting relationships were found among TF families across developmental stages and tissue types. As shown in Figure 3a, the ratio of up- and downregulated TFs varies across all the tissues. Among the major TF families, bHLH and ERF (ETHYLENE RESPONSE FACTOR) did not vary too much across developmental stages or tissue types. However, WRKY showed great variations in FD3, FD4, and flower; downregulated in FD3 and FD4, while upregulated in flower. CYC TFs were gradually downregulated from FD1 to FD4 and showed complete downregulation in FD5. MADS were mainly upregulated in the flower development stages, while most of them were downregulated in the roots. Similarly, COLs were also upregulated during flower development and remained low in non-reproductive parts (Figure 3a). 
a

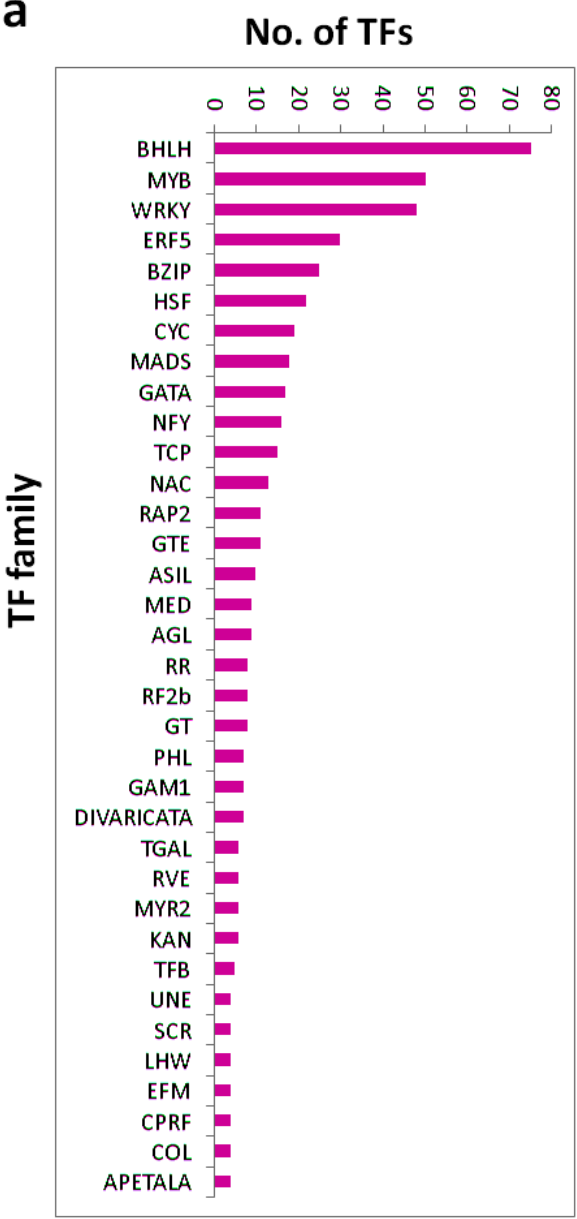

b



0

$-1$

$-2$



C

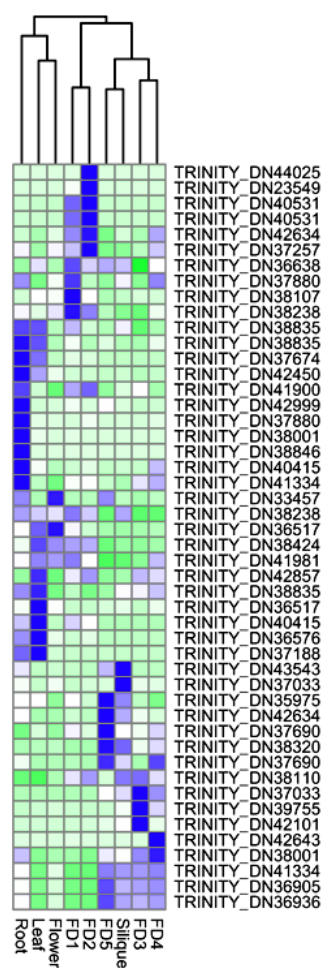

d

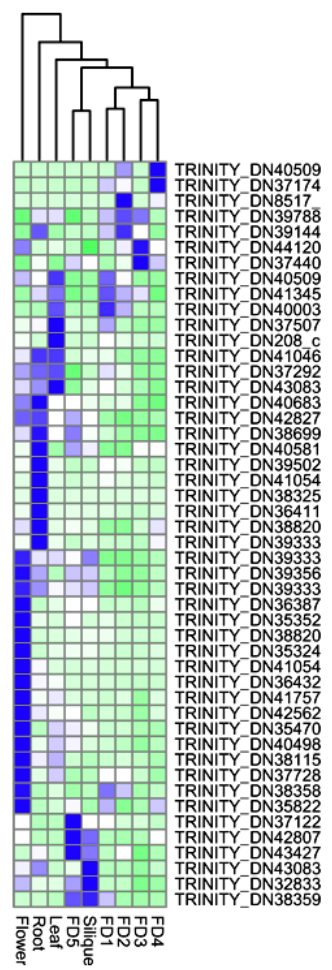

Figure 2. Abundance of TF families; (a) number of TFs in all major families, (b) bHLH TF family, (c) MYB TF family, (d) WRKY TF family.

Comparing the floral development stages (Figure 3b), FD1 showed the most upregulated TFs (435), whereas FD5 showed the most downregulated TFs (495). A reciprocal trend can be seen between upregulated and downregulated TFs across five stages of flower development (Figure $3 b$ ). Upregulation showed a decreasing trend from FD1 to FD5, whereas downregulation showed an increasing trend from FD1 to FD5. The maximum difference of up- and downregulated TFs was observed in FD5, wherein 495 TFs showed upregulation and 192 TFs shown downregulation. However, in the mature flower an equal number of up- and downregulated TFs can be seen (Figure 3c). These results suggest that the gene expression profiles of the samples obtained at the early and late flowering stages are quite different, and many genes may be highly expressed at the initial stage of flowering (FD5), and their expression may decrease as the flowers bloom and with age. 
a

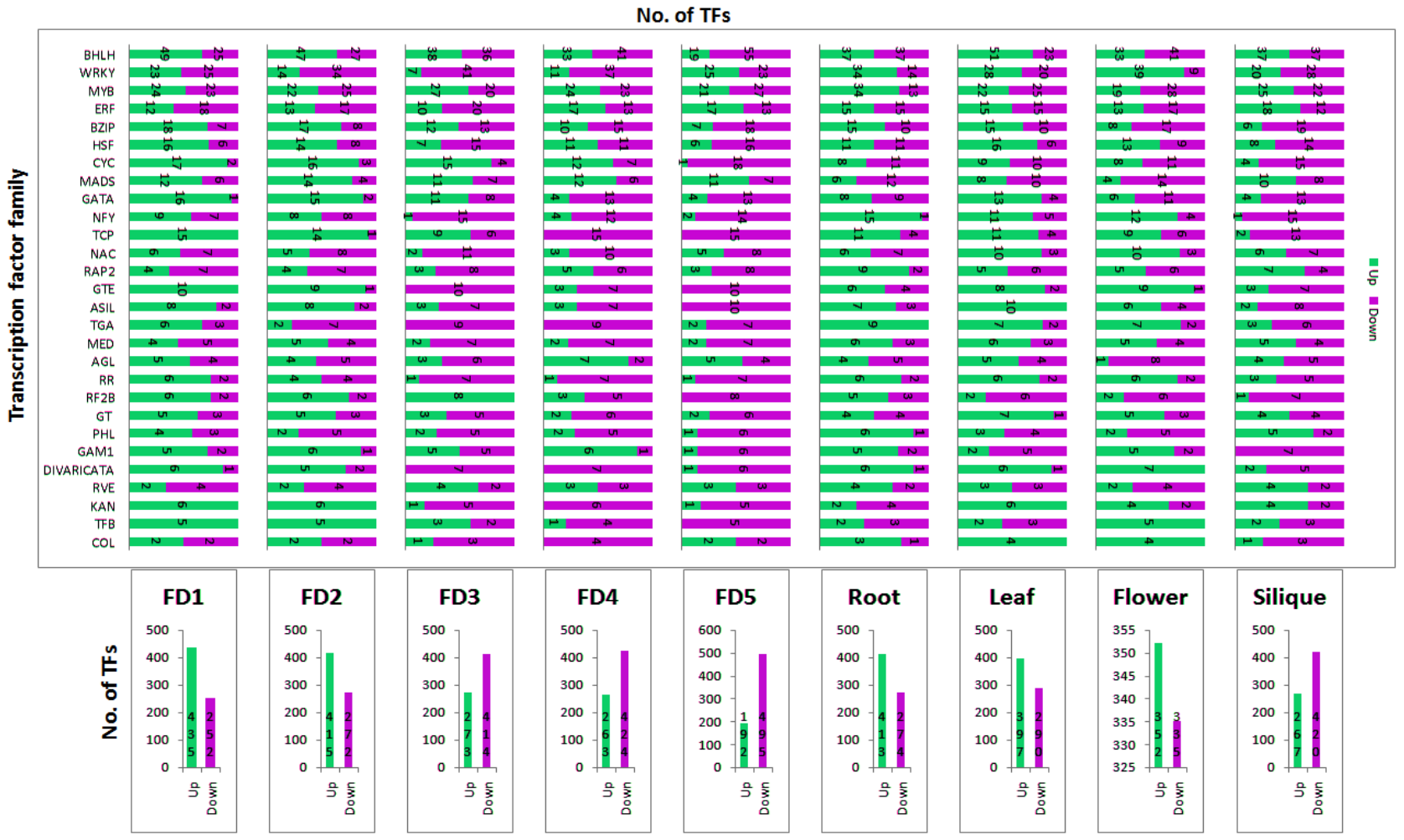

C

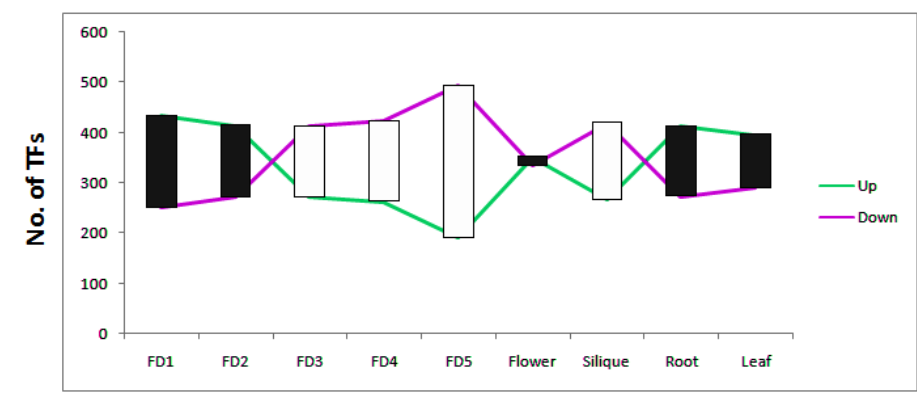

Figure 3. (a) Number of up- and downregulated TFs, (b) stage specific number of up- and downregulated TFs, (c) relation of up- and downregulation across different tissues.

\subsection{Top 20 Highly Differential TFs}

The edgeR package of $\mathrm{R}$ was used to filter the top 20 highly differential TFs across nine tissues. These include some of the known regulators of flowering reported in model plants and other orchid species. Notably, this highly differential set of genes contained eight MADS-box TFs and three MYBs. Cluster analysis of these 20 DEGs showed that FD1 and FD2 in early flower developmental stages were clustered together, while FD3, FD4, and FD5 in the late stages were clustered together. The former mainly showed upregulated expression of class E MADS gene SEP, class B MADS gene AP3, TCP, and two MYBs, while the latter showed a higher expression of class C MADS gene AG-like and class D MADS gene STK (SEEDSTICK), as well as WRKY and EFR genes. In vegetative organs, the accumulation of the flowering suppressor genes SVP and PIF1 (Phytochrome-interacting factor) was higher. This indicated a close relation between these genes with floral organ development. By analyzing the interaction proteins of these key genes, we found many other important factors linked together, for example, SVP is linked with leafy (LFY) and FT. Moreover, MYB12 involves the chemical homeostasis along with TCP3 (Figure 4b). Important biological processes were observed in the top 20 highly differential TFs, such as flower development (GO: 0009908), flower whorl development (GO: 0048438), and photoperiodism and flowering (GO: 0048573) (Figure 4c). Most of the highly differential 
DEGs identified in A. graminifolia are similar to the genes identified in other orchids, such as Dendrobium catenatum, Phalaenopsis equestris, Cymbidium goeringii, and Cymbidium sinense (Supplementary Table S3).

a



TRINITY_DN40713_c0_g1 Ethylene-responsive transcription factor RAP2-11 RAP2-11 TRINITY_DN38729_c2_g6 Transcription factor PIF4-like isoform X1 PIF1 TRINITY_DN37987_c6_g3 MADS26 SVP TRINITY_DN41304_c2_g5 SEPALLATA-like MADS-box protein 2 SEP1 TRINITY_DN43745_c2_g6 B-class MADS-box protein AP3-2, partial AP3-2 TRINITY_DN39560_c1_g3 B-class MADS-box protein AP3-3 MADS16 TRINITY DN38100 c1 g7 MADS box protein SEP1 SEP1 TRINITY_DN36675_c1_g11 TCP transcription factor TCP3 TRINITY_DN39074_c2_g6 Transcription factor ILI5-like ILI5 TRINITY_DN40531_c5_g3 MYB transcription factor 3 MYB12 TRINITY_DN40531_c5_g2 MYB transcription factor 3 MYB3 TRINITY DN39887_c1 g3 MADS-box transcription factor MADS-box TRINITY_DN38082_c1_g13 Transcription factor GTE9-like isoform X1 GTE9-like TRINITY_DN40509_c0_g7 PREDICTED: probable WRKY transcription factor 2 WRKY34 TRINITY_DN37033_c1_g9 MYB transcription factor 15 MYB57 TRINITY_DN36646_c2_g5 MYB transcription factor RVE8 TRINITY_DN39887_c1_g4 AGAMOUS-like transcription factor AG1 TRINITY_DN36389_c0_g1 SEEDSTICK-like protein AGL11 TRINITY_DN37669_c2_g5 Ethylene-responsive transcription factor ERF110-like ERF110 TRINITY_DN42783_c1_g1 NAC transcription factor 25 NAM-B2

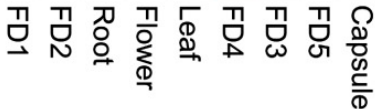

b

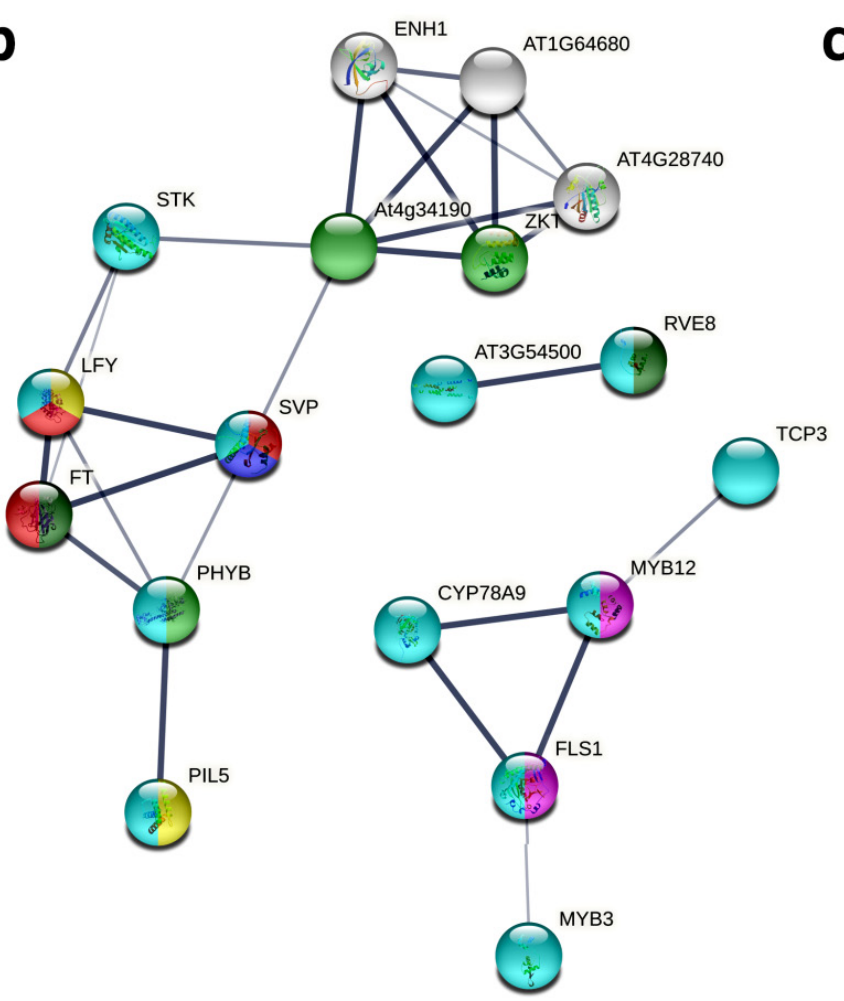

C

GO:0009058: Biosynthetic process

GO:0051555: Flavonol biosynthetic process

GO:0009740: Gibberellic acid mediated signaling pathway

GO:0048573: Photoperiodism, flowering

GO:0015979: Photosynthesis

GO:0009908: Flower development

GO:0048438: Floral whorl development

Figure 4. Top 20 most differential TFs; (a) heatmap of top $20 \mathrm{TFs}$, (b) string-based protein-protein interaction of some candidates of top $20 \mathrm{TFs}$, (c) enrichment of important biological process terms related to flowering and hormones in top 20 TFs shown in part ' $\mathbf{b}$ '. 


\subsection{Stage-Specific Highly Upregulated TFs}

Stage-specific TFs were identified to know the specific response of each stage and tissue type. The minimum number of TFs (12) was expressed specifically in FD5, whereas the maximum number of TFs (92) was specific to the root (Figure 5a). Regarding the floral development, 32 TFs showed the highest expression in FD2, followed by FD1 (28) and FD4 (24). Generally, the differentially expressed genes were similar in the two adjacent developmental stages. Most of the TFs upregulated in FD1 were also upregulated, although less intensely, in FD2. Similarly the FD3-specific TFs were also upregulated in less intensity in FD4. By contrast, the expression profile of the root was the most specific. Most of the genes were highly expressed here and downregulated in other tissues.

To obtain a better understanding of the stage-specificity, the top 10 highly expressed TFs were sketched together to elaborate their expression patterns across tissues (Figure 5b). FD1 showed upregulation in multiple TF families, including MADS14, bHLH117, and ETERNAL TAPETUM1 (EAT1) with their roles in flower development. Only one of the FD1 TFs was downregulated in FD2, and they were completely downregulated from FD3-FD5.

The TFs showing the highest expression in FD2 were also upregulated in FD1. They were gradually downregulated in other stages of flower development and tissue types. In FD1, two flowering-related TFs MADS14 and EAT1 showed the highest expressions. MADS14 is 88\% identical to FRUITFUL-like MADS protein in Cymbidium goeringii (accession no. KX347442.1). EAT1 is similar to Phalaenopsis equestris EAT1 TF (88\% similarity; accession no. XM_020741375.1). Interestingly, FD2 showed the highest expression of some famous regulators of flowering, such as MADS6, MADS16, TCP3, and MYB12. MADS6 and MADS16 are $91 \%$ and $90 \%$ similar, respectively, to Dendrobium catenatum MADS6 (accession no. XM_020843535.2), and MADS16 (accession no. XM_020822071.2). In FD3, the upregulated TFs were more specific compared to FD1 and FD2. CCA1 is the important circadian clock regulator of flower timing upregulated in this stage. It is similar (87\%) to Dendrobium catenatum CCA1 protein (accession no. XM_020842163.2).

The expression trend of FD4- and FD5-specific TFs was very different compared to rest of the stages of flower development. WRKY34 is specifically expressed in FD4. It is similar (76\%) to Gossypium raimondii TF WRKY34 (accession no. XM_012605143.1). In FD5, AGL80 (86\% similar with Phalaenopsis equestris agamous-like MADS-box protein AGL80; accession no. XM_020720626.1), and ERF12 (91\% similar with Musa acuminata subsp. ethylene-responsive transcription factor 12-like; accession no. XM_009398926.2) were the notable flowering related TFs (Supplementary Table S3). Interestingly, when comparing the reproductive parts of A. graminifolia, the TFs upregulated in the mature flower were mostly downregulated in other reproductive parts. This indicates that the expression of these genes increases at the end of the flowering process, which may be related to the flower senescence.

TFs in the root showed the maximum expression values, wherein the cumulative log2 fold change was greater than 70 compared to the rest of the tissues. Furthermore, the TFs expressed here were completely downregulated in all other plant parts or floral development stages. Similarly, the leaf also showed distinct TFs, which mostly downregulated in other tissues, except for the flower and FD1, where only a few TFs showed upregulation with negligible intensities (Figure 5b). 
a

문


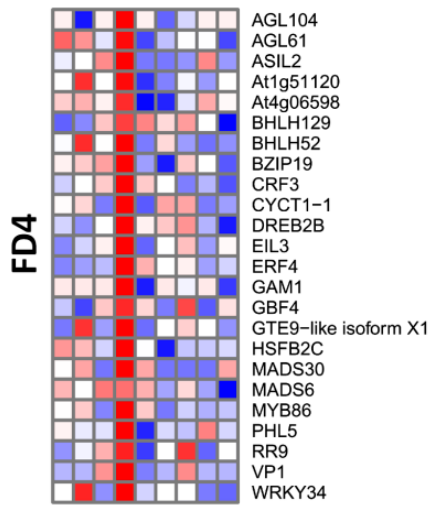



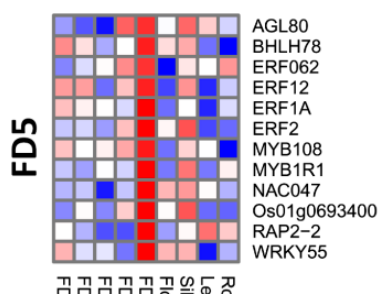

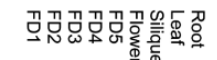
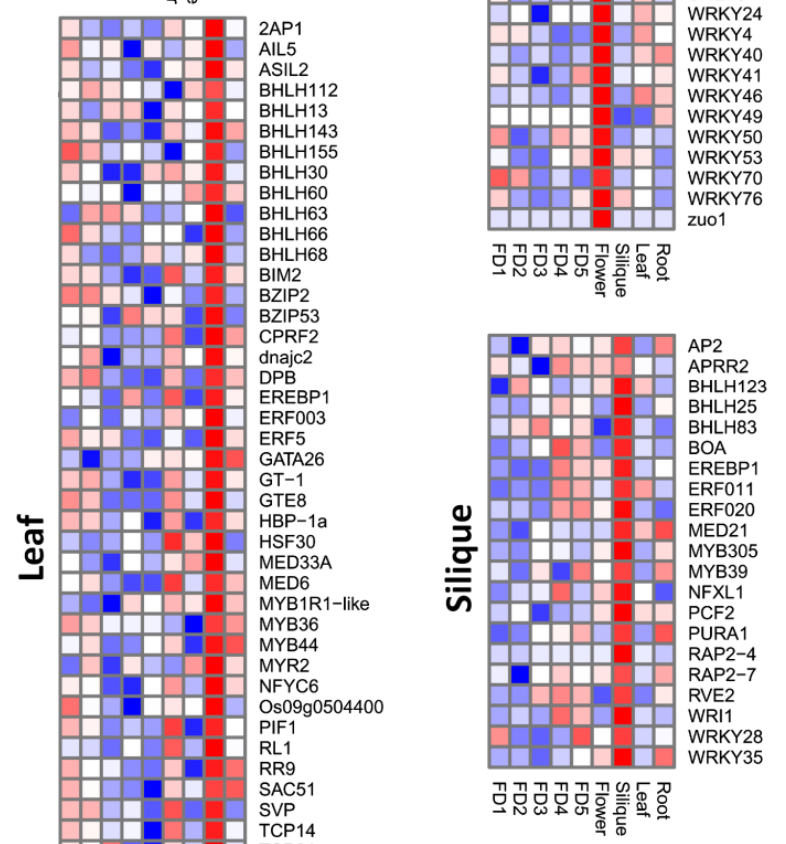


ฏัญ

\begin{tabular}{lll} 
RPN4 \\
\hline-1
\end{tabular} \begin{tabular}{lll}
\hline-1 & \\
\hline$R R 21$ \\
$R R 4$
\end{tabular} \begin{tabular}{lll}
\hline & \\
\hline & & \\
SCP 20 \\
TCP2
\end{tabular} \begin{tabular}{|l|l} 
TCP24 \\
\hline \\
\hline
\end{tabular} WRKY4
WRKY40
WRKY41 WRKY46
WRKY49
WRKY50
WRKY WRKY53
WRKY70 -

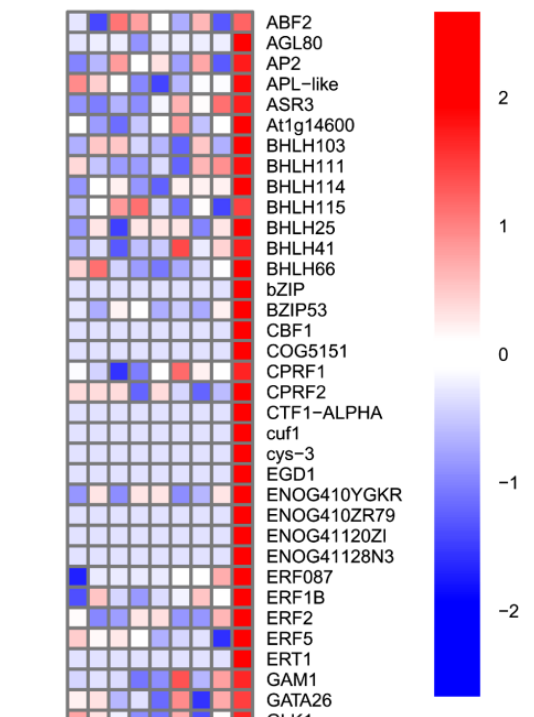

$\stackrel{\square}{\circ}$
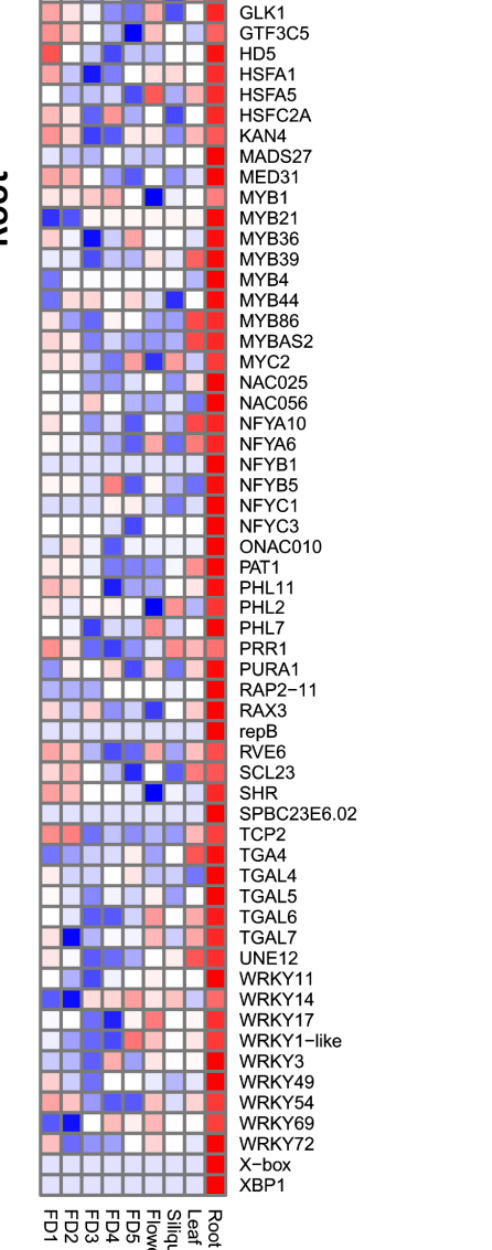

Figure 5. Cont. 




Figure 5. Stage-specific TFs; (a) heatmap of stage specific TFs, (b) log2-foldchange expression trends of top 10 stage-specific TFs.

\subsection{The qRT-PCR Validation of Some Selected TFs in Flower Regulation}

The expression trends of ten randomly selected TFs were ascertained (Figure 6). The results from quantitative PCR showed that the expressions of most of the genes were consistent with that of transcriptomic expressions (Supplementary Figure S2). For example, MADS6, MADS14, and EAT1 showed the highest expressions in FD1 as compared to other stages of floral development (Figure 6a). However, in other tissues, the expression was the highest in silique compared to the mature flower, leaf, and root, where it was negligible (Figure 6b). In FD2, TCP3, SEP, and MADS16, showed the highest expressions; while in other tissues, their expression was the highest in silique. The maximum expression of $R R 9$ was observed in FD4 among all stages of floral development and it was also abundant in silique and mature flowers. Regarding FD5, MYB108 and ERF12 were the most abundant compared to the rest of the floral development stages. However, in other tissue types, MYB108 showed high expression in the root, silique, and mature flower, while ERF12 was abundant in the silique. 
a
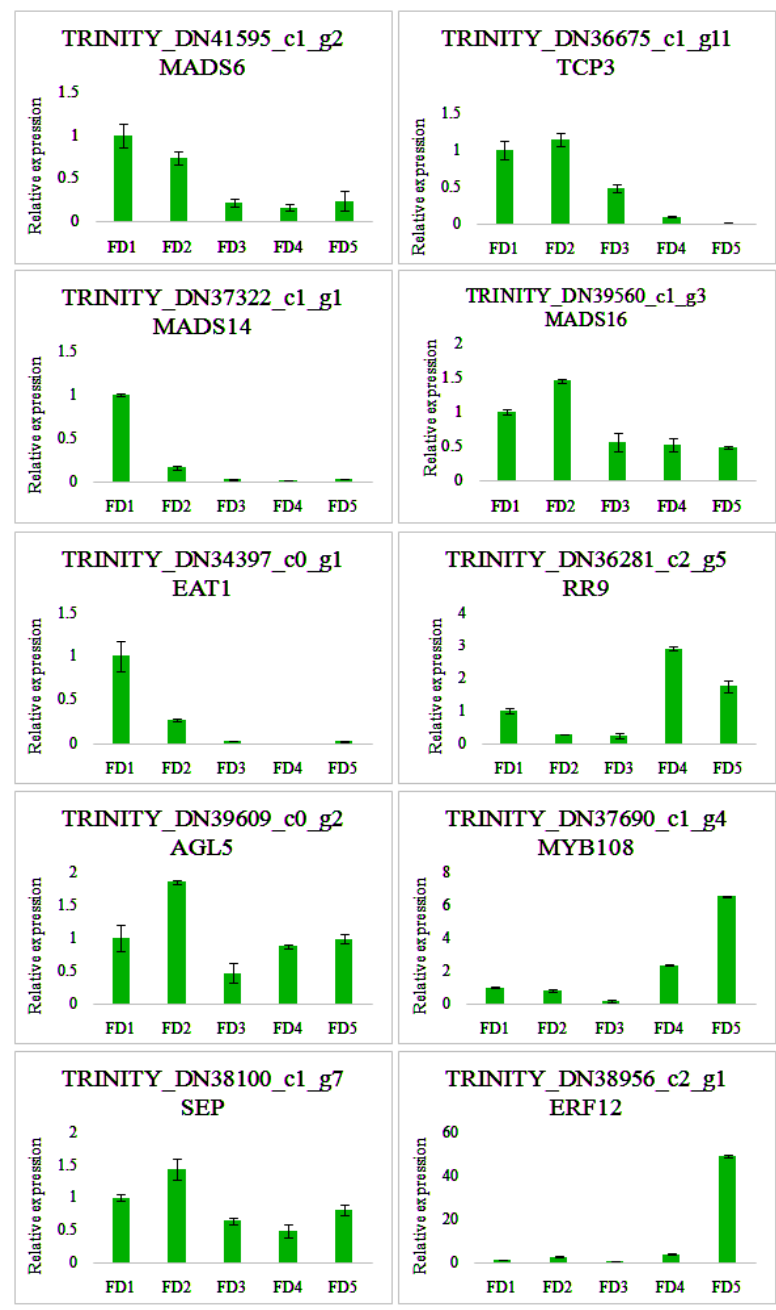



TRINITY_DN36281_c2_g5
RR9

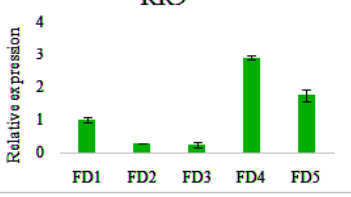

TRINITY_DN37690_c1_g4
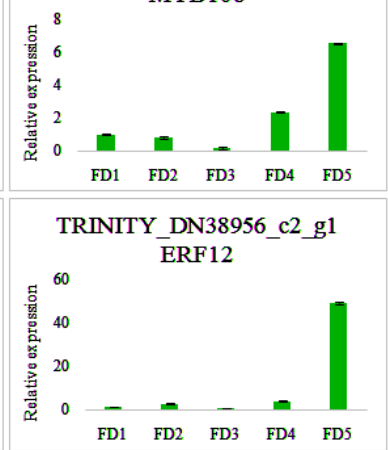

b

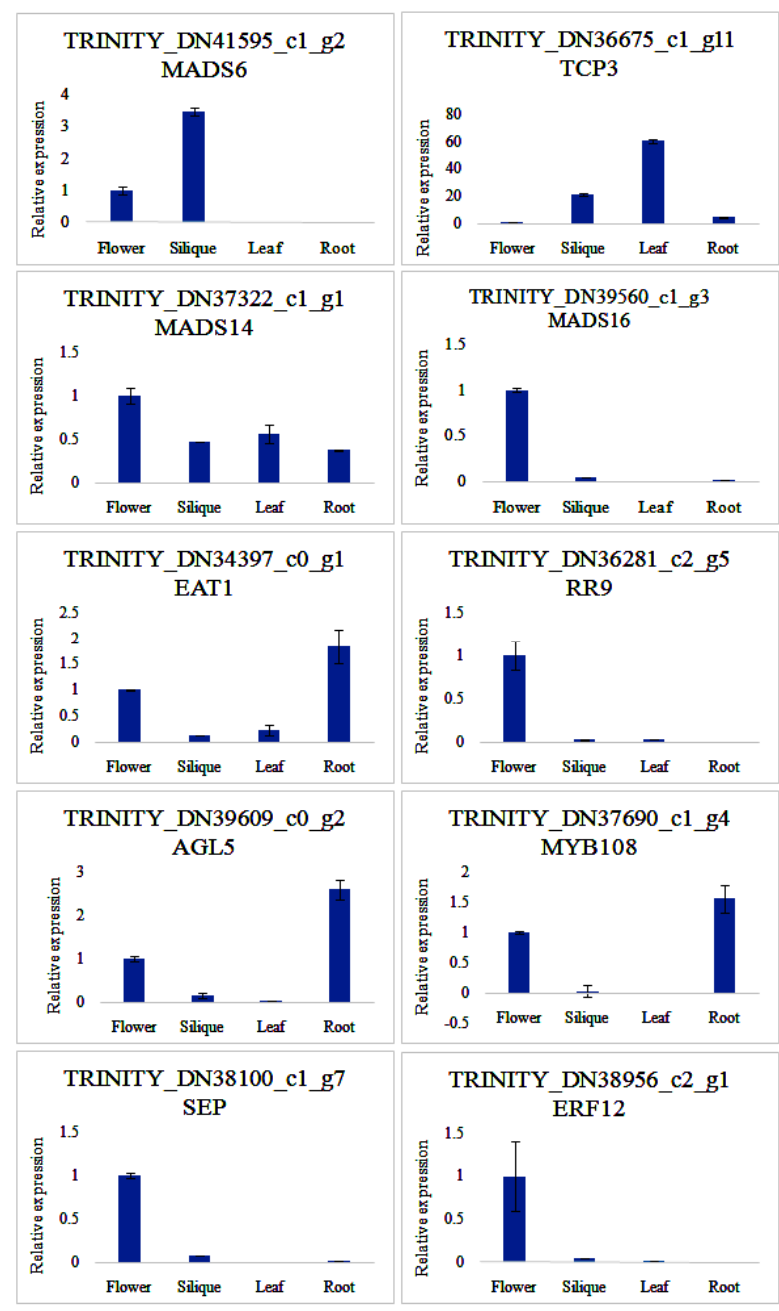

Figure 6. qRT-PCR validation of selected TFs; (a) qRT-PCR expression of selected TFs in five stages of flower development, (b) qRT-PCR expression of selected TFs in other tissue types.

\section{Discussion}

Currently, transcriptome has been widely used to identify genes regulating unique plant traits [31-34]. In our study, 25,353 unigenes were assembled from five floral development stages and four tissue types of A. graminifolia. Using the DEGs as reference, 687 transcription factors were identified in the floral organs and other tissues. Flower development in A. graminifolia may be coregulated by a variety of TFs. Our findings, thus, provide the genetic information for the functional characterization of these TFs in orchid flower development.

More than 35 TF families were identified that may play a role in the regulation of flower development in A. graminifolia. Our data suggested some important regulators of flower development, hormones, and flowering time that have been previously identified in other orchids, such as Dendrobium catenatum, Phalaenopsis equestris, Cymbidium goeringii, and Cymbidium sinense (Supplementary Table S3). HECATE 3 (HEC3) regulates phytochrome signaling in the light pathway [35], while one CCA1, 2 LHY, and 4 CO-like TFs were identified from the DEGs in this study. Together with $H E C 3$, they may regulate the circadian clock and photoperiod pathways in the flower development of A. graminifolia. Gibberellins (GA) are the endogenous signaling molecules that are involved in flowering control. Multiple TFs are known to respond to GA, while ERF and bHLH are involved in ethylene and auxin signaling, respectively [2]. Ethylene and auxin may act antagonistically 
or synergistically with GA during the flowering regulation [36-39]. The Viviparous-1 (VP1) encodes a B3 type TF and works during ABA signaling pathway [40]. ABA-INSENSITIVE3 (ABI3) is the ortholog of VP1 in Arabidopsis [41]. Thus, our transcriptomic data generated TF regulators of major hormones involved in flowering regulation.

Four families of TFs, ZFP, WRKY, bHLH, and MYB have been known to involve flowering regulation in many plant species [2]. In Arabidopsis, some members of bHLH, MYB, and WRKY families, such as bHLH48 and 60; EARLY FLOWERING MYB PROTEIN (EFM); WRKY12, 13, and 71 have been documented to regulate flowering through the transcription of FLOWERING LOCUS T (FT) [33,42-44]. MYB, bHLH, and WRKY were the most abundant TF families in our transcriptomic data. Moreover, important MADS-box TFs, including MADS6 (agamous-like 6, AGL6), AGL5, MADS14, MADS16, sepallata (SEP), and apetala3 were identified in the present study. AGL6 and SEP3 play pivotal roles in the regulation of flowering time and floral organ development $[45,46]$.

Our data suggested a rich number of TFs that expressed significantly to particular stages of flower development, including FD1 to FD5. MADS14 is an APETALA1 (AP1)/FRUITFUL (FUL)-like MADS-box TF involved in floral meristem identity [47-49]. It was induced in shoot apical meristem (SAM) during transition to reproductive growth in Oryza sativa [50]. Our qRT-PCR result showed that MADS-14 was highly expressed in FD1 as compared to other stages of flower development, proposing its important role in meristem identity. Another MADS-box TF SEP showed the highest expression in FD2, while MADS6 showed higher expressions in FD1 and FD2 compared to other stages. MADS16, an AP3-PI subfamily gene, was observed in A. graminifolia among all the stages of floral development. These results indicated spatiotemporal expression patterns of MADS-box TFs along with flower development. TCP3 functions as a transcriptional activator of CO [51] and it showed the highest expression in FD2 which is, according to the transcriptomic expression (Supplementary Figure S2a). CCA1 (CIRCADIAN CLOCK ASSOCIATED1) is a circadian clock component associated with flowering time. It represses SOC1 and GI through direct interaction with their promoters, implying a connection between the flowering pathways and the circadian clock [52]. It was highly expressed in FD3, as shown by transcriptomic data (Figure 5, FD3).

Arabidopsis MYB108 regulates jasmonate-mediated stamen maturation by acting together with MYB24 [53]. MYB108 plays an important role in the correct timing for anther dehiscence, and in combination with MYB24, it regulates filament elongation, pollen viability and anther dehiscence; moreover, its expression is regulated by upstream TF MYB21 [53]. MYB108 was highly expressed in stage 5 of flower development of A. graminifolia (Figure 6a), as suggested by qRT-PCR and transcriptomic data (Supplementary Figure S2a). ETERNAL TAPETUM1 (EAT1) is a bHLH TF involved in tapetal cell-fate decision [54]. The highest expression of EAT1 was observed in FD1. BHLH49 is an auxin regulator during embryo identity [55]. RR9 is a member of type-B response regulators (RRs) and plays important role in cytokinin signaling [56]. RR9 showed the highest expression in FD4, which is according to its transcriptomic expression (Supplementary Figure S2a). WRKY34 induces proteolysis of FRI to regulate flowering in the vernalization pathway [57]. ETHYLENE RESPONSE FACTOR12 (ERF12), in Arabidopsis, is an ortholog of MULTIFLORET SPIKELET1 in rice and it pleiotropically affects floral phyllotaxy, meristem identity, and organ initiation in plants [58]. Dependent on the photoperiod, ERF12 is a putative transcriptional repressor and integrates into the AP2 (APETALA2) pathway to regulate floral organ identity and floral timing $[58,59]$. In line with the transcriptomic data, ERF12 was abundantly expressed in FD5 compared to other stages, where its expression was negligible (Figure 6a). The expression of TFs validated through qRT-PCR was almost similar to the transcriptomic expression for stages of flower development (Supplementary Figure S2). However, for other tissue types, some TFs showed different expression intensities compared to transcriptomic expression. 
The regulatory mechanisms for continuous flowering are intimately linked to dormancy and bud release, but the basic molecular mechanisms are not well elucidated. However, transcriptomic and physiological analyses indicate increased expression of FT/FD and GA biosynthesis-related genes, which promote growth, and concomitant downregulation of ABA pathway genes transiently release dormancy to facilitate bud break [60-62]. However, ABA can counter this effect in two ways: it regulates GA levels by inhibiting SVP during short-day photoperiod and downregulates FT/FD at low temperatures.

SHORT VEGETATIVE PHASE (SVP), a flowering-time regulator, positively regulates TCP18 [TEOSINTE BRANCHED, CYCLOIDEA, PCR (TCP)], a mediator of temperaturedependent bud break [63]. Both proteins function in a temperature-sensitive transcriptional module that mediates bud break. Cymbidium goeringii SVP2 interacts with CgAP1 and CgSOC1, similar to reports in Arabidopsis, Antirrhinum, petunia, and rice, which forms the basis of MADS-box TF function [64]. AP1 may serve as a hub between the interacting proteins of the flower induction pathway (such as SOC1 and SVP) and the floral organ identity proteins [45]. In temperature- and photoperiod-dependent flowering pathways, SVP interacts with FLC and FLM (FLOWERING LOCUS M), causing FT repression and flowering [65-67]. Moreover, the GA and ABA hormonal pathway genes are targeted by SVP in bud break [68]. In this work, two homologs of Arabidopsis thaliana SVP were identified in the transcriptome and both showed highest expression levels in leaves. It was almost undetectable in the five stages of $A$. graminifolia flower development, unlike the expression patterns of Cymbidium goeringii SVPS that were trapped in the early stage of flower development (Figure 5). Among the TCP homologs identified, TCP3 exhibited the highest expression levels in the first three stages of floral development. TCP21 was expressed in FD1 and leaves.

Considering that the regulatory mechanisms for continuous flowering are intimately linked to dormancy and bud release, the most important characteristic of Arundina graminifolia is that the initiation of flowering and the floral development are completed rapidly, without going through a dormancy period. Unlike other orchids with narrow flowering span, A. graminifolia flowers all year round (Figure 7a). Therefore, studying molecular basis of continuous flowering is of significant interest. Our data show multiple regulatory routes for flowering regulation in A. graminifolia (Figure 7b). We found candidate TFs from multiple pathways: vernalization, circadian clock, photoperiod, and hormonal pathways. These pathways interact with floral integrators (MADS-box) to regulate flowering. FT/FD could act as a central receiver of signals to control the flowering time through APETALA (AP1, AP2 and AP3) and SOC1. Moreover, the rapid decrease of SVP genes from the early stage may be an important promoting factor to ensure the rapid development of flower organs without dormancy. However, extended research would be needed to reveal these assumptions. 
a



\begin{tabular}{|c|c|c|c|}
\hline \multirow{2}{*}{ Year1 } & Phalaenopsis & & Flower initiation \\
\hline & Flower-development & Blooming & \\
\hline Year2 & & & \\
\hline
\end{tabular}


b



Figure 7. Comparison of flowering pattern of bamboo orchid with Phalaenopsis and Cymbidium (a) and the hypothetical model of the flowering regulation involving key transcriptional factors in Arundina graminifolia (b). 


\section{Conclusions}

With the above in mind, we identified a large number of TFs through RNA-seq, which may contribute important roles in different regulatory pathways of A. graminifolia flowering. These pathways include the photoperiod, vernalization, hormone, and circadian clock pathways (Figure 7b). The identification of key TFs involved in these pathways can do a great deal to reveal the genetic regulatory network that drives continuous flowering specifically in A. graminifolia, and seasonal flowering in other orchids, in general. However, further studies are required to fully unravel the functions of these transcription factors.

Supplementary Materials: The following are available online at https://www.mdpi.com/article/10 .3390 /biom11060771/s1, Figure S1: Floral organ development and morphogenesis of A. graminifolia, Figure S2: Comparison of qRT-PCR expression intensities of selected TFs (a) with that of transcriptomic expression as FPKM (b), Table S1: Individual ratio (\%) of annotation of DEGs related to flowering and hormonal regulation, Table S2: Gene IDs and FPKM values of the TFs used to filter stage-specific TFs, Table S3: Similarity index of some of the important flowering related TFs in Arundina graminifolia with other orchids and angiosperms.

Author Contributions: G.Z. and F.Y. planned the research. C.L., J.W. and Y.W. did the sampling. Y.W., J.G., J.J. and C.Z. performed the experiments. S.A. and F.Y. analyzed the data and wrote the manuscript. G.Z. and F.Y. revised the manuscript. All authors have read and agreed to the published version of the manuscript.

Funding: This work was supported by grants from National Key Technologies R\&D Program (2019FD1001003, 2018YFD10004); National Natural Science Foundation of China (31672184,31902065); R\&D plan in key areas of Guangdong Province (2018B020202001), Natural Science Foundation of Guangdong province (2017A030312004); Guangdong modern agricultural industrial technology system flower innovation team expert project (2021KJ121); Guangzhou scientific research project (201904020026).

Institutional Review Board Statement: Not applicable.

Informed Consent Statement: Not applicable.

Data Availability Statement: All the relevant data are provided along with the manuscript as Supplementary Files.

Acknowledgments: We are thankful to funding agencies for funding and Plant Editors for providing professional services for language editing and the final polishing of our manuscript.

Conflicts of Interest: The authors declare no conflict of interest.

\section{References}

1. Bäurle, I.; Dean, C. The timing of developmental transitions in plants. Cell 2006, 125, 655-664. [CrossRef]

2. Zhou, A.; Sun, H.; Dai, S.; Feng, S.; Zhang, J.; Gong, S.; Wang, J. Identification of Transcription Factors Involved in the Regulation of Flowering in Adonis Amurensis Through Combined RNA-seq Transcriptomics and iTRAQ Proteomics. Genes 2019, $10,305$. [CrossRef] [PubMed]

3. Fornara, F.; de Montaigu, A.; Coupland, G. SnapShot: Control of flowering in Arabidopsis. Cell 2010, 141, 550-550.e2. [CrossRef]

4. Ausin, I.; Alonso-Blanco, C.; Martinez-Zapater, J.-M. Environmental regulation of flowering. Int. J. Dev. Biol. 2004, 49, 689-705. [CrossRef] [PubMed]

5. Mutasa-Göttgens, E.; Hedden, P. Gibberellin as a factor in floral regulatory networks. J. Exp. Bot. 2009, 60, 1979-1989. [CrossRef] [PubMed]

6. Simpson, G.G. The autonomous pathway: Epigenetic and post-transcriptional gene regulation in the control of Arabidopsis flowering time. Curr. Opin. Plant Biol. 2004, 7, 570-574. [CrossRef] [PubMed]

7. Wang, J.W.; Czech, B.; Weigel, D. miR156-regulated SPL transcription factors define an endogenous flowering pathway in Arabidopsis thaliana. Cell 2009, 138, 738-749. [CrossRef]

8. Teotia, S.; Tang, G. To bloom or not to bloom: Role of microRNAs in plant flowering. Mol. Plant 2015, 8, 359-377. [CrossRef] [PubMed]

9. Zhang, J.; Wu, K.; Zeng, S.; Teixeira da Silva, J.A.; Zhao, X.; Tian, C.E.; Xia, H.; Duan, J. Transcriptome analysis of Cymbidium sinense and its application to the identification of genes associated with floral development. BMC Genom. 2013, 14, 279. [CrossRef]

10. Komeda, Y. Genetic regulation of time to flower in Arabidopsis thaliana. Annu. Rev. Plant Biol. 2004, 55, 521-535. [CrossRef] 
11. Imaizumi, T.; Kay, S.A. Photoperiodic control of flowering: Not only by coincidence. Trends Plant Sci. 2006, 11, 550-558. [CrossRef] [PubMed]

12. Niwa, Y.; Ito, S.; Nakamichi, N.; Mizoguchi, T.; Niinuma, K.; Yamashino, T.; Mizuno, T. Genetic linkages of the circadian clock-associated genes, TOC1, CCA1 and LHY, in the photoperiodic control of flowering time in Arabidopsis thaliana. Plant Cell Physiol. 2007, 48, 925-937. [CrossRef] [PubMed]

13. Berry, S.; Dean, C. Environmental perception and epigenetic memory: Mechanistic insight through FLC. Plant J. 2015, 83, 133-148. [CrossRef] [PubMed]

14. Bastow, R.; Mylne, J.S.; Lister, C.; Lippman, Z.; Martienssen, R.A.; Dean, C. Vernalization requires epigenetic silencing of FLC by histone methylation. Nature 2004, 427, 164-167. [CrossRef]

15. Searle, I.; He, Y.; Turck, F.; Vincent, C.; Fornara, F.; Kröber, S.; Amasino, R.A.; Coupland, G. The transcription factor FLC confers a flowering response to vernalization by repressing meristem competence and systemic signaling in Arabidopsis. Genes Dev. 2006, 20, 898-912. [CrossRef] [PubMed]

16. Wood, C.C.; Robertson, M.; Tanner, G.; Peacock, W.J.; Dennis, E.S.; Helliwell, C.A. The Arabidopsis thaliana vernalization response requires a polycomb-like protein complex that also includes VERNALIZATION INSENSITIVE 3. Proc. Natl. Acad. Sci. USA 2006, 103, 14631-14636. [CrossRef]

17. Sung, S.; Amasino, R.M. Vernalization in Arabidopsis thaliana is mediated by the PHD finger protein VIN3. Nature 2004, 427, 159-164. [CrossRef]

18. Lee, J.H.; Yoo, S.J.; Park, S.H.; Hwang, I.; Lee, J.S.; Ahn, J.H. Role of SVP in the control of flowering time by ambient temperature in Arabidopsis. Genes Dev. 2007, 21,397-402. [CrossRef]

19. Wang, J.-W. Regulation of flowering time by the miR156-mediated age pathway. J. Exp. Bot. 2014, 65, 4723-4730. [CrossRef]

20. Wang, M.; Hoekstra, S.; van Bergen, S.; Lamers, G.E.; Oppedijk, B.J.; van der Heijden, M.W.; de Priester, W.; Schilperoort, R.A. Apoptosis in developing anthers and the role of ABA in this process during androgenesis in Hordeum vulgare L. Plant Mol. Biol. 1999, 39, 489-501. [CrossRef]

21. Yu, H.; Ito, T.; Zhao, Y.; Peng, J.; Kumar, P.; Meyerowitz, E.M. Floral homeotic genes are targets of gibberellin signaling in flower development. Proc. Natl. Acad. Sci. USA 2004, 101, 7827-7832. [CrossRef] [PubMed]

22. Aloni, R.; Aloni, E.; Langhans, M.; Ullrich, C.I. Role of auxin in regulating Arabidopsis flower development. Planta 2006, 223, 315-328. [CrossRef] [PubMed]

23. Lindsay, D.L.; Sawhney, V.K.; Bonham-Smith, P.C. Cytokinin-induced changes in CLAVATA1 and WUSCHEL expression temporally coincide with altered floral development in Arabidopsis. Plant Sci. 2006, 170, 1111-1117. [CrossRef]

24. McConn, M. The critical requirement for linolenic acid is pollen development, not photosynthesis, in an Arabidopsis mutant. Plant Cell 1996, 8, 403-416. [CrossRef]

25. Rieu, I.; Wolters-Arts, M.; Derksen, J.; Mariani, C.; Weterings, K. Ethylene regulates the timing of anther dehiscence in tobacco. Planta 2003, 217, 131-137. [CrossRef]

26. Auberon, F.; Olatunji, O.J.; Krisa, S.; Antheaume, C.; Herbette, G.; Bonté, F.; Mérillon, J.-M.; Lobstein, A. Two new stilbenoids from the aerial parts of Arundina graminifolia (Orchidaceae). Molecules 2016, 21, 1430. [CrossRef]

27. Hooker, J. Gnetaceae. Flora Br. India 1890, 5, 640-643.

28. Seidenfaden, G.; Wood, J.J.; Holttum, R.E. The Orchids of Peninsular Malaysia and Singapore; Olsen \& Olsen: Fredensborg, Denamrk, 1992.

29. Grabherr, M.G.; Haas, B.J.; Yassour, M.; Levin, J.Z.; Thompson, D.A.; Amit, I.; Adiconis, X.; Fan, L.; Raychowdhury, R.; Zeng, Q. Full-length transcriptome assembly from RNA-Seq data without a reference genome. Nat. Biotechnol. 2011, 29, 644. [CrossRef]

30. Ahmad, S.; Yuan, C.; Yang, Q.; Yang, Y.; Cheng, T.; Wang, J.; Pan, H.; Zhang, Q. Morpho-physiological integrators, transcriptome and coexpression network analyses signify the novel molecular signatures associated with axillary bud in chrysanthemum. BMC Plant Biol. 2020, 20, 145. [CrossRef]

31. Wang, Y.; Xiao, X.; Wang, X.; Zeng, J.; Kang, H.; Fan, X.; Sha, L.; Zhang, H.; Zhou, Y. RNA-Seq and iTRAQ reveal the dwarfing mechanism of dwarf polish wheat (Triticum polonicum L.). Int. J. Biol. Sci. 2016, 12, 653. [CrossRef]

32. Ye, X.; Wang, H.; Chen, P.; Fu, B.; Zhang, M.; Li, J.; Zheng, X.; Tan, B.; Feng, J. Combination of iTRAQ proteomics and RNA-seq transcriptomics reveals multiple levels of regulation in phytoplasma-infected Ziziphus jujuba Mill. Hortic. Res. 2017, 4, 17080. [CrossRef] [PubMed]

33. Li, W.; Wang, H.; Yu, D. Arabidopsis WRKY transcription factors WRKY12 and WRKY13 oppositely regulate flowering under short-day conditions. Mol. Plant 2016, 9, 1492-1503. [CrossRef]

34. Abbas, H.M.K.; Huang, H.-X.; Wang, A.-J.; Wu, T.-Q.; Xue, S.-D.; Ahmad, A.; Xie, D.-S.; Li, J.-X.; Zhong, Y.-J. Metabolic and transcriptomic analysis of two Cucurbita moschata germplasms throughout fruit development. BMC Genomics 2020, 21, 365. [CrossRef] [PubMed]

35. Zhu, L.; Xin, R.; Bu, Q.; Shen, H.; Dang, J.; Huq, E. A negative feedback loop between PHYTOCHROME INTERACTING FACTORs and HECATE proteins fine-tunes photomorphogenesis in Arabidopsis. Plant Cell 2016, 28, 855-874. [CrossRef] [PubMed]

36. Zhang, Z.-L.; Ogawa, M.; Fleet, C.M.; Zentella, R.; Hu, J.; Heo, J.-O.; Lim, J.; Kamiya, Y.; Yamaguchi, S.; Sun, T.-p. Scarecrow-like 3 promotes gibberellin signaling by antagonizing master growth repressor DELLA in Arabidopsis. Proc. Natl. Acad. Sci. USA 2011, 108, 2160-2165. [CrossRef] 
37. Sarnowska, E.A.; Rolicka, A.T.; Bucior, E.; Cwiek, P.; Tohge, T.; Fernie, A.R.; Jikumaru, Y.; Kamiya, Y.; Franzen, R.; Schmelzer, E. DELLA-interacting SWI3C core subunit of switch/sucrose nonfermenting chromatin remodeling complex modulates gibberellin responses and hormonal cross talk in Arabidopsis. Plant Physiol. 2013, 163, 305-317. [CrossRef]

38. Santner, A.; Calderon-Villalobos, L.I.A.; Estelle, M. Plant hormones are versatile chemical regulators of plant growth. Nat. Chem. Biol. 2009, 5, 301-307. [CrossRef]

39. Licausi, F.; Ohme-Takagi, M.; Perata, P. APETALA 2/Ethylene Responsive Factor (AP 2/ERF) transcription factors: Mediators of stress responses and developmental programs. New Phytol. 2013, 199, 639-649. [CrossRef]

40. Carbonero, P.; Iglesias-Fernández, R.; Vicente-Carbajosa, J. The AFL subfamily of B3 transcription factors: Evolution and function in angiosperm seeds. J. Exp. Bot. 2017, 68, 871-880. [CrossRef]

41. Suzuki, M.; Kao, C.Y.; Cocciolone, S.; McCarty, D.R. Maize VP1 complements Arabidopsisabi3 and confers a novel ABA/auxin interaction in roots. Plant J. 2001, 28, 409-418. [CrossRef]

42. Yan, Y.; Shen, L.; Chen, Y.; Bao, S.; Thong, Z.; Yu, H. A MYB-domain protein EFM mediates flowering responses to environmental cues in Arabidopsis. Dev. Cell 2014, 30, 437-448. [CrossRef] [PubMed]

43. Yu, Y.; Liu, Z.; Wang, L.; Kim, S.G.; Seo, P.J.; Qiao, M.; Wang, N.; Li, S.; Cao, X.; Park, C.M. WRKY 71 accelerates flowering via the direct activation of FLOWERING LOCUS T and LEAFY in Arabidopsis thaliana. Plant J. 2016, 85, 96-106. [CrossRef] [PubMed]

44. Li, Y.; Wang, H.; Li, X.; Liang, G.; Yu, D. Two DELLA-interacting proteins bHLH48 and bHLH60 regulate flowering under long-day conditions in Arabidopsis thaliana. J. Exp. Bot. 2017, 68, 2757-2767. [CrossRef]

45. Honma, T.; Goto, K. Complexes of MADS-box proteins are sufficient to convert leaves into floral organs. Nature 2001, 409, 525-529. [CrossRef] [PubMed]

46. Koo, S.C.; Bracko, O.; Park, M.S.; Schwab, R.; Chun, H.J.; Park, K.M.; Seo, J.S.; Grbic, V.; Balasubramanian, S.; Schmid, M. Control of lateral organ development and flowering time by the Arabidopsis thaliana MADS-box Gene AGAMOUS-LIKE6. Plant J. 2010, 62, 807-816. [CrossRef] [PubMed]

47. Abe, M.; Kobayashi, Y.; Yamamoto, S.; Daimon, Y.; Yamaguchi, A.; Ikeda, Y.; Ichinoki, H.; Notaguchi, M.; Goto, K.; Araki, T. FD, a bZIP protein mediating signals from the floral pathway integrator FT at the shoot apex. Science 2005, 309, 1052-1056. [CrossRef] [PubMed]

48. Wigge, P.A.; Kim, M.C.; Jaeger, K.E.; Busch, W.; Schmid, M.; Lohmann, J.U.; Weigel, D. Integration of spatial and temporal information during floral induction in Arabidopsis. Science 2005, 309, 1056-1059. [CrossRef]

49. Corbesier, L.; Vincent, C.; Jang, S.; Fornara, F.; Fan, Q.; Searle, I.; Giakountis, A.; Farrona, S.; Gissot, L.; Turnbull, C. FT protein movement contributes to long-distance signaling in floral induction of Arabidopsis. Science 2007, 316, 1030-1033. [CrossRef]

50. Kobayashi, K.; Yasuno, N.; Sato, Y.; Yoda, M.; Yamazaki, R.; Kimizu, M.; Yoshida, H.; Nagamura, Y.; Kyozuka, J. Inflorescence meristem identity in rice is specified by overlapping functions of three AP1/FUL-like MADS box genes and PAP2, a SEPALLATA MADS box gene. Plant Cell 2012, 24, 1848-1859. [CrossRef]

51. Kubota, A.; Ito, S.; Shim, J.S.; Johnson, R.S.; Song, Y.H.; Breton, G.; Goralogia, G.S.; Kwon, M.S.; Cintrón, D.L.; Koyama, T. TCP4-dependent induction of CONSTANS transcription requires GIGANTEA in photoperiodic flowering in Arabidopsis. PLoS Genet. 2017, 13, e1006856. [CrossRef]

52. Lu, S.X.; Webb, C.J.; Knowles, S.M.; Kim, S.H.; Wang, Z.; Tobin, E.M. CCA1 and ELF3 Interact in the control of hypocotyl length and flowering time in Arabidopsis. Plant Physiol. 2012, 158, 1079-1088. [CrossRef]

53. Mandaokar, A.; Browse, J. MYB108 acts together with MYB24 to regulate jasmonate-mediated stamen maturation in Arabidopsis. Plant Physiol. 2009, 149, 851-862. [CrossRef] [PubMed]

54. Ono, S.; Liu, H.; Tsuda, K.; Fukai, E.; Tanaka, K.; Sasaki, T.; Nonomura, K.-I. EAT1 transcription factor, a non-cell-autonomous regulator of pollen production, activates meiotic small RNA biogenesis in rice anther tapetum. PLoS Genet. 2018, 14, e1007238. [CrossRef] [PubMed]

55. Radoeva, T.; Lokerse, A.S.; Llavata-Peris, C.I.; Wendrich, J.R.; Xiang, D.; Liao, C.-Y.; Vlaar, L.; Boekschoten, M.; Hooiveld, G.; Datla, R. A robust auxin response network controls embryo and suspensor development through a basic helix loop helix transcriptional module. Plant Cell 2019, 31, 52-67. [CrossRef] [PubMed]

56. Worthen, J.M.; Yamburenko, M.V.; Lim, J.; Nimchuk, Z.L.; Kieber, J.J.; Schaller, G.E. Type-B response regulators of rice play key roles in growth, development and cytokinin signaling. Development 2019, 146, dev174870. [CrossRef]

57. Hu, X.; Kong, X.; Wang, C.; Ma, L.; Zhao, J.; Wei, J.; Zhang, X.; Loake, G.J.; Zhang, T.; Huang, J. Proteasome-mediated degradation of FRIGIDA modulates flowering time in Arabidopsis during vernalization. Plant Cell 2014, 26, 4763-4781. [CrossRef]

58. Chandler, J.; Werr, W. A phylogenetically conserved APETALA2/ethylene response factor, ERF12, regulates arabidopsis floral development. Plant Mol. Biol. 2020, 102, 39-54. [CrossRef]

59. Yant, L.; Mathieu, J.; Dinh, T.T.; Ott, F.; Lanz, C.; Wollmann, H.; Chen, X.; Schmid, M. Orchestration of the floral transition and floral development in Arabidopsis by the bifunctional transcription factor APETALA2. Plant Cell 2010, 22, 2156-2170. [CrossRef]

60. Horvath, D.P.; Chao, W.S.; Suttle, J.C.; Thimmapuram, J.; Anderson, J.V. Transcriptome analysis identifies novel responses and potential regulatory genes involved in seasonal dormancy transitions of leafy spurge (Euphorbia esula L.). BMC Genom. 2008, 9 , 536. [CrossRef]

61. Bai, S. Transcriptome analysis of Japanese pear (Pyrus pyrifolia Nakai) flower buds transitioning through endodormancy. Plant Cell Physiol. 2013, 54, 1132-1151. [CrossRef] 
62. Rinne, P.L. Chilling of dormant buds hyperinduces FLOWERING LOCUS T and recruits GA-inducible 1,3-beta-glucanases to reopen signal conduits and release dormancy in Populus. Plant Cell 2011, 23, 130-146. [CrossRef] [PubMed]

63. Singh, R.K.; Miskolczi, P.; Maurya, J.P.; Bhalerao, R.P. A tree ortholog of SHORT VEGETATIVE PHASE floral repressor mediates photoperiodic control of bud dormancy. Curr. Biol. 2019, 29, 128-133.e122. [CrossRef]

64. Yang, F.; Zhu, G.; Wei, Y.; Gao, J.; Liang, G.; Peng, L.; Lu, C.; Jin, J. Low-temperature-induced changes in the transcriptome reveal a major role of CgSVP genes in regulating flowering of Cymbidium goeringii. BMC Genom. 2019, 20, 53. [CrossRef] [PubMed]

65. Fujiwara, S.; Oda, A.; Yoshida, R.; Niinuma, K.; Miyata, K.; Tomozoe, Y.; Tajima, T.; Nakagawa, M.; Hayashi, K.; Coupland, G. Circadian clock proteins LHY and CCA1 regulate SVP protein accumulation to control flowering in Arabidopsis. Plant Cell 2008, 20, 2960-2971. [CrossRef] [PubMed]

66. Gregis, V.; Sessa, A.; Dorca-Fornell, C.; Kater, M.M. The Arabidopsis floral meristem identity genes AP1, AGL24 and SVP directly repress class B and C floral homeotic genes. Plant J. 2009, 60, 626-637. [CrossRef] [PubMed]

67. Tao, Z.; Shen, L.; Liu, C.; Liu, L.; Yan, Y.; Yu, H. Genome-wide identification of SOC1 and SVP targets during the floral transition in Arabidopsis. Plant J. 2012, 70, 549-561. [CrossRef]

68. Singh, R.K.; Maurya, J.P.; Azeez, A.; Miskolczi, P.; Tylewicz, S.; Stojkovič, K.; Delhomme, N.; Busov, V.; Bhalerao, R.P. A genetic network mediating the control of bud break in hybrid aspen. Nat. Commun. 2018, 9, 4173. [CrossRef] 